Meta-Analysis

\title{
Prognostic value of long noncoding RNA ZFAS1 in various carcinomas: a meta-analysis
}

\author{
Dan Dong ${ }^{1, *}$, Zhongyi Mu ${ }^{1,2, *}$, Wei Wang ${ }^{1}$, Na Xin ${ }^{1}$, Xiaowen Song ${ }^{1}$, Yue Shao ${ }^{1}$ and \\ Chenghai Zhao' \\ ${ }^{1}$ Department of Pathophysiology, College of Basic Medical Science, China Medical University, Shenyang, People's Republic \\ of China \\ ${ }^{2}$ Department of Urology, Cancer Hospital of China Medical University, Liaoning Cancer Hospital and Institute, Shenyang, \\ People's Republic of China \\ *These authors contributed equally to this work
}

Correspondence to: Chenghai Zhao, email: zhaochenghai71@163.com

Keywords: zinc finger antisense 1, long noncoding RNA, prognosis, meta-analysis

Received: May 07, $2017 \quad$ Accepted: August 28, $2017 \quad$ Published: September 20, 2017

Copyright: Dong et al. This is an open-access article distributed under the terms of the Creative Commons Attribution License 3.0 (CC BY 3.0), which permits unrestricted use, distribution, and reproduction in any medium, provided the original author and source are credited.

\section{ABSTRACT}

A number of studies have revealed that zinc finger antisense 1 (ZFAS1), a long noncoding RNA (IncRNA), is aberrantly regulated in various cancers, and high ZFAS1 expression is associated with poor prognosis and increased risk of lymph node metastasis (LNM). This meta-analysis was conducted to identify the potential value of ZFAS1 as a biomarker for cancer prognosis. We searched electronic database PubMed, Web of Science, and China Wanfang Data (up to June 1, 2017) to collect all relevant studies and explore the association of ZFAS1 expression with overall survival (OS) and LNM. The results showed that cancer patients with high ZFAS1 expression had a worse OS than those with low ZFAS1 expression (HR: 1.94, 95\% confidence interval [CI]: 1.41-2.47, $P<0.001$ ), and high ZFAS1 expression was significantly associated with LNM (OR: 2.60, 95\% CI: 1.54-4.42, $P<0.001$ ). Subgroup analysis revealed that high ZFAS1 expression was significantly related to high incidence of LNM in subgroups of sample size more than 88 (OR: 3.16, 95\% CI: $2.06-4.86, P<0.001$ ), non-digestive system malignancies (OR: 4.05, 95\% CI: 2.49-6.60, $P<0.001$ ), and studies reported in 2017 (OR: 4.86, 95\% CI: 2.67-8.84, $P<0.001$ ) without significant heterogeneity. Further meta-regression by the covariates showed that tumor type, sample size, quality score, cut off value and publication year did not result in the inter-study heterogeneity. In conclusion, the present meta-analysis demonstrates that high ZFAS1 expression may potentially serve as a reliable biomarker for poor clinical outcome in various cancers.

\section{INTRODUCTION}

Cancer is one of the leading causes of morbidity and mortality worldwide today [1]. Although encouraging progress in treatment for cancer has been achieved, the 5 -year survival rate remains low and the majority of patients die due to relapse and metastases [2]. The ideal prognostic marker helps predict the tumor prognosis, which is of great significance for designing reasonable plans for disease surveillance and treatment. Recently, researchers focused on tumor biomarkers and have identified numerous potential biomarkers for tumor prognosis and treatment [3-4]. However, it is urgently needed for the sensitive and specific biomarkers for prognosis of patients with cancers.

Long noncoding RNAs (lncRNAs) are nonproteincoding transcripts with length of 200 nucleotides, which have been dismissed as transcriptional "noise" in the past decade $[5,6]$. Nowadays, accumulating evidence shows that lncRNAs play tremendous roles in cell proliferation, 
differentiation, apoptosis and transformation [7-9]. Clinicopathologic studies have suggested that lncRNAs are related to prognosis and metastasis of various tumors, therefore, they may be sensitive and specific biomarkers for the prediction of cancer progression and prognosis [10-13].

Zinc finger antisense 1 (ZFAS1) is a newly identified lncRNA, which has attracted widespread attention recently. Aberrant high expression of ZFAS1 was reported in a series of human cancers, including hepatocellular carcinoma [14], gastric cancer [15-17], melanoma [18], lung cancer [19], glioma [20] and colorectal cancer [21-23]. It was observed that high ZFAS1 expression was associated with metastasis and prognosis, thus ZFAS1 may be a potential biomarker for prognosis. This current meta-analysis was performed to explore the correlation of ZFAS1 expression with clinical outcome of cancer patients, and further determine whether ZFAS1 could serve as an effective biomarker for metastasis and prognosis.

\section{MATERIALS AND METHODS}

\section{Search strategy}

We searched for potentially eligible literatures published up to June 2017 through PubMed, Embase, Web of Science, Chinese Wan Fang and CNKI database for the meta-analysis. The search strategy used both MeSH terms and free-text words to increase sensitivity. The keywords for the search were as follows: "ZFAS1 and cancer", "long non-coding RNA ZFAS1", "IncRNA ZFAS1", "ZFAS1". Articles were limited to English-language and Chineselanguage publications. Meanwhile, reference lists of relevant articles were also reviewed to identify potentially eligible papers.

\section{Inclusion and exclusion criteria}

In this meta-analysis, eligible studies had to meet the following standards: 1) studies with a cohort design, 2) studies investigating the correlation between ZFAS1 expression and cancer patients, 3) studies in which ZFAS1 expression in primary tumor tissues was measured by realtime quantitative reverse transcription PCR (qRT-PCR), 4) studies with sufficient original data for calculating odd ratios (ORs), hazard ratios (HRs) and their 95\% confidence interval $(95 \% \mathrm{CI})$. If an article only provided survival curves without offering HR and 95\% CI directly, appropriate data were extracted from the survival curves using Engauge Digitizer 4.1 software, and $\log \mathrm{HR}$ and selogHR were calculated according to Tierney et al. [24]. The following criteria were used to exclude studies: 1) duplicate publications; 2) studies of case reports, letters, and reviews; 3) studies without usable data.

\section{Date extraction}

Two investigators extracted the data independently through a same standard. Any disagreement was consulted with a third investigator. The following details were extracted: first author, publication year, country of origin, cancer type, detection method of ZFAS1, total number of patients, number of high ZFAS1 expression group and low expression group, number of patients with LNM, the HR and the corresponding 95\% confidence interval (CI) for overall survival (OS).

\section{Statistical analysis}

ORs and 95\% CI were used to evaluate the relationship between ZFAS1 expression and LNM, and HRs and 95\% CI were used to assess the effect of ZFAS1 expression on the survival. In order to evaluate the heterogeneity of the included studies, Cochrane $Q$-test and $\mathrm{I}^{2}$ statistics were performed by using Stata 12.0 Software (Stata, College Station, TX, USA). If there was a significantly statistical heterogeneity $\left(\mathrm{I}^{2} \geq 50 \%\right.$ or $P \leq 0.05)$ among the studies, we used the random-effects model to analyze the results, and performed subgroup and sensitivity analysis to dissect the heterogeneity. If the heterogeneity was absent, the fixed-effects model was applied to this meta-analysis. In addition, the Stata 12.0 Software was used to evaluate the sensitivity of the studies. Publication bias was evaluated by Begg's test and Egger's test, $P<0.05$ was considered statistically significant. Forest plots were used to dispaly the metaanalysis results, and Begg's funnel plots were used to show publication bias.

The method reported by Wacholder et al. [25] was used to analyze the false positive report probability (FPRP) and statistical power of each significant correlation. A prior probability of 0.1 was set to detect an OR of $0.67 / 1.50$ (protective/risk effects). When the FPRP value was lower than 0.2 , the correlation was noteworthy. Statistical power and FPR $P$ value were calculated using the Excel spreadsheet provided by Wacholder et al. [25].

\section{RESULTS}

\section{Characteristics of eligible studies}

A flow diagram of literature search process was presented in Figure 1. After searching PubMed, Embase, Web of Science, Chinese Wan Fang and CNKI database, we selected twelve studies ranging 2015 to 2017 based on the inclusion criteria, and these studies were all from People's Republic of China. Seven different types of cancer were evaluated in the meta-analysis, with one case of non-small cell lung cancer (NSCLC), three cases of gastric cancer (GC), three cases of colorectal cancer 
(CRC), one case of hepatocellular carcinoma (HCC), two case of glioma, one case of melanoma and one case of ovarian cancer (OC).

Table 1 summarized the main characteristics of the included twelve studies enrolling 1075 participants, with the mean patient sample size of 80.5 (range 54-173). In these studies, ZFAS1 expression in tumor tissues was determined by qRT-PCR. All studies comprised a high ZFAS1 expression group and a low ZFAS1 expression group. Nine studies investigated the association between ZFAS1 expression and OS, and nine studies assessed the association between ZFAS1 expression and LNM. HRs and $95 \%$ CIs were directly extracted from five studies, and calculated by survival curves in five studies. ORs and $95 \%$ CIs were directly extracted from nine studies.

\section{Relationship between ZFAS1 and OS}

Nine studies consisting of 841 patients reported the OS according to levels of ZFAS1 expression, and the median sample size was 88 (range 54-173) in this metaanalysis. Given that there was no heterogeneity across

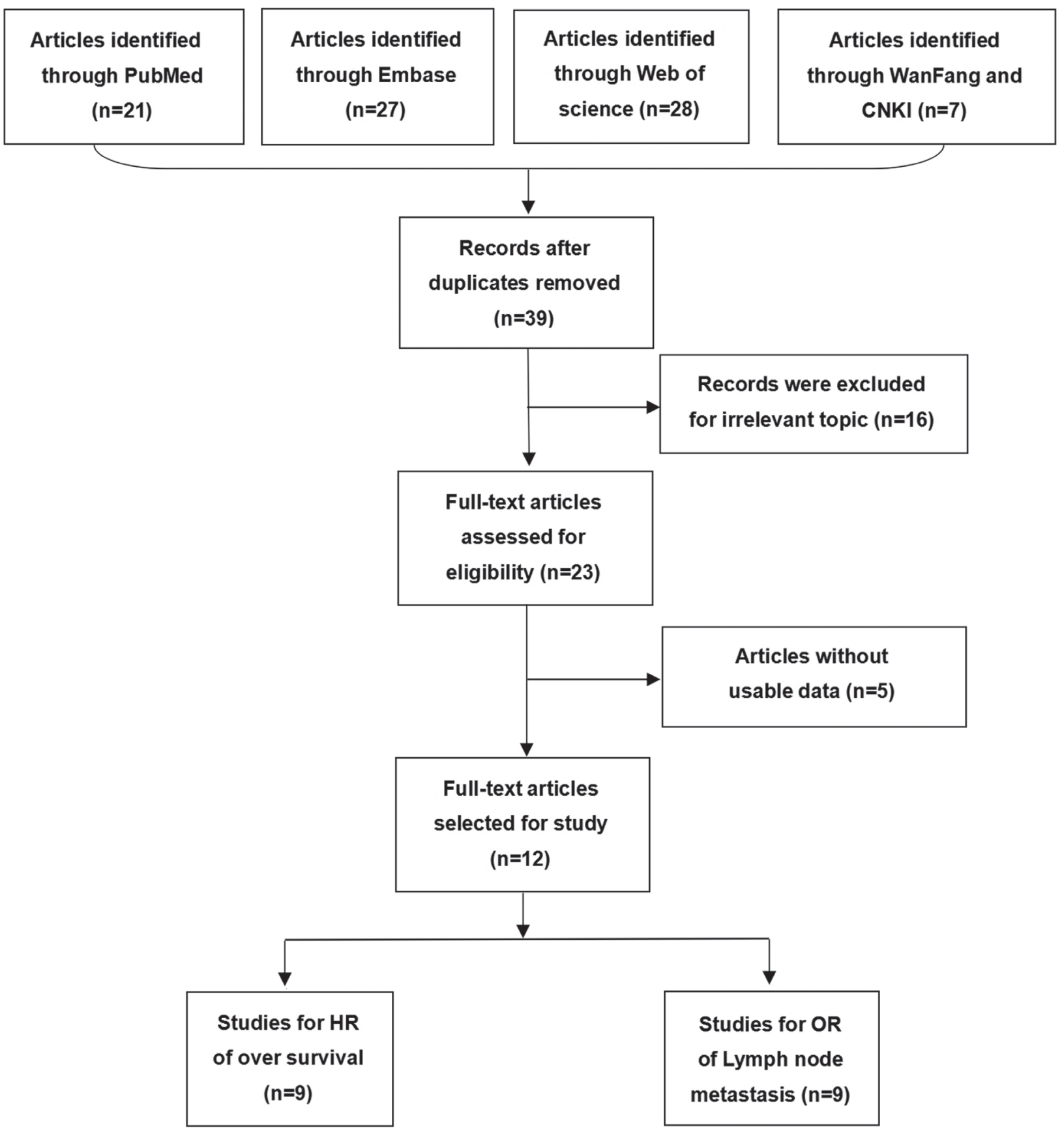

Figure 1: Flowchart presenting the steps of literature search and selection. 
Table 1: Characteristics of ZFAS1 studies included in the meta-analysis

\begin{tabular}{|c|c|c|c|c|c|c|c|c|c|c|c|c|c|c|}
\hline \multirow[b]{2}{*}{ First auhor } & \multirow[b]{2}{*}{ Year } & \multirow[b]{2}{*}{ Country } & \multirow[b]{2}{*}{$\begin{array}{l}\text { Cancer } \\
\text { Type }\end{array}$} & \multirow[b]{2}{*}{$\begin{array}{c}\text { Sample } \\
\text { size }\end{array}$} & \multicolumn{4}{|c|}{ ZFAS1 expression } & \multirow[b]{2}{*}{$\begin{array}{c}\text { Detection } \\
\text { method }\end{array}$} & \multirow[b]{2}{*}{$\begin{array}{l}\text { Cut-off } \\
\text { value }\end{array}$} & \multirow[b]{2}{*}{ Outcome } & \multirow[b]{2}{*}{ HR estimate } & \multirow[b]{2}{*}{$\begin{array}{l}\text { NOS } \\
\text { score }\end{array}$} & \multirow[b]{2}{*}{ IF value } \\
\hline & & & & & $\begin{array}{l}\text { High } \\
\text { with } \\
\text { LNM }\end{array}$ & $\begin{array}{c}\text { High } \\
\text { without } \\
\text { LNM }\end{array}$ & $\begin{array}{l}\text { Low } \\
\text { with } \\
\text { LNM }\end{array}$ & $\begin{array}{c}\text { Low } \\
\text { without } \\
\text { LNM }\end{array}$ & & & & & & \\
\hline Wang et al. & 2016 & China & $\mathrm{CRC}$ & 159 & 50 & 29 & 38 & 42 & qRT-PCR & Median & OS & Reported & 7 & 1.543 \\
\hline Tian et al. & 2016 & China & NSCLC & 173 & 58 & 27 & 34 & 54 & qRT-PCR & NA & OS & Reported & 6 & 1.778 \\
\hline Nie et al. & 2016 & China & GC & 54 & 12 & 15 & 16 & 11 & qRT-PCR & Median & OS & Survival curve & 8 & 5.168 \\
\hline Pan et al. & 2017 & China & GC & 94 & 48 & 10 & 19 & 17 & qRT-PCR & NA & - & - & 6 & 3.502 \\
\hline Fang et al. & 2016 & China & $\mathrm{CC}$ & 73 & 15 & 21 & 6 & 31 & qRT-PCR & NA & OS & Survival curve & 7 & 3.452 \\
\hline Lv et al. & 2017 & China & glioma & 69 & - & - & - & - & qRT-PCR & Median & OS & Reported & 6 & 3.650 \\
\hline Li et al. & 2015 & China & $\mathrm{HCC}$ & 88 & - & - & - & - & qRT-PCR & Median & OS & Survival curve & 7 & 9.122 \\
\hline Wu et al. & 2016 & China & $\mathrm{CRC}$ & 67 & 12 & 22 & 15 & 18 & qRT-PCR & Median & - & - & 6 & NA \\
\hline Wei et al. & 2017 & China & melanoma & 88 & 38 & 8 & 22 & 20 & qRT-PCR & Median & OS & Reported & 8 & 1.706 \\
\hline Zhang et al. & 2016 & China & $\mathrm{GC}$ & 104 & 25 & 27 & 8 & 44 & qRT-PCR & Median & OS & Reported & 8 & 1.706 \\
\hline Xia et al. & 2017 & China & $\mathrm{OC}$ & 60 & 16 & 14 & 4 & 26 & qRT-PCR & NA & OS & Survival curve & 7 & 5.168 \\
\hline Gao et al. & 2017 & China & glioma & 46 & - & - & - & - & qRT-PCR & NA & OS & Survival curve & 6 & 1.971 \\
\hline
\end{tabular}

these studies $\left(\mathrm{I}^{2}=0.0 \%, P=0.964\right.$; Figure 2$)$, the fixedeffects model was applied to estimate the pooled HRs and the respective 95\% CIs. As shown in Figure 2, our results revealed that high ZFAS1 expression predicted poor OS in various cancers (pooled HR: 1.94, 95\% CI: 1.41-2.47, $P<0.001$; fixed-effect).

\section{Relationship between ZFAS1 and LNM}

Nine studies reported the number of patients with LNM in a total of 872 individuals. The median sample size was 88 (range 54-173). As shown in Figure 3, the randomeffects model was adopted for the significant heterogeneity

\begin{tabular}{|c|c|c|}
\hline Study ID & $\mathrm{HR}(95 \% \mathrm{Cl})$ & Weight \% \\
\hline Wang et al (2016) & $2.13(1.01,4.55)$ & 8.98 \\
\hline Tian et al (2016) & $1.83(1.04,3.83)$ & 14.39 \\
\hline Lv et al (2017) & $1.92(1.06,3.47)$ & 19.22 \\
\hline Li et al (2015) & $2.22(1.09,4.35)$ & 10.54 \\
\hline Nie et al (2016) & $2.04(0.81,5.26)$ & 5.66 \\
\hline Wei et al (2017) & $2.73(1.25,4.97)$ & 8.08 \\
\hline Zhang et al (2016) & $2.95(1.32,7.04)$ & 3.42 \\
\hline gao et al (2017) & $2.15(0.79,5.88)$ & 4.32 \\
\hline xia et al (2017) & $1.39(0.69,2.79)$ & 25.40 \\
\hline Overall (I-squared $=0.0 \%, p=0.964$ ) & $1.94(1.41,2.47)$ & 100.00 \\
\hline$Z=7.19 P<0.001$ & & \\
\hline NOTE: Weights are from fix effects analysis & & \\
\hline $\begin{array}{c}1 \\
-7.04\end{array}$ & 04 & \\
\hline
\end{tabular}

Figure 2: Forest plot for the association between ZFAS1 expression with OS. 
$\left(\mathrm{I}^{2}=67.1 \%, P=0.002\right)$. Our results revealed that high ZFAS1 expression was significantly associated with LNM (pooled OR: 2.60, 95\% CI: 1.54-4.42, $P<0.001$, randomeffects). Because of the significant heterogeneity between studies, subgroups were analyzed based on the tumor type, sample size, quality score and publication year (Table 2 ). Our data revealed that high ZFAS1 expression was related to high incidence of LNM in subgroups of sample size more than 88 (OR: $3.16,95 \%$ CI: $2.06-4.86, P<0.001$ ), non-digestive system malignancies (OR: $4.05,95 \% \mathrm{CI}$ : 2.49-6.60, $P<0.001$ ), studies reported in 2017 (OR: $4.86,95 \%$ CI: $2.67-8.84, P<0.001)$ without significant heterogeneity. In addition, we further performed metaregression by the covariates including tumor type, sample size, quality score and publication year. As shown in Table 2 and Figure 4, those factors did not result in the inter-study eterogeneity.

\section{FPRP test}

The significant associations were investigated by using the FPRP test. For a prior probability of 0.1 , high ZFAS1 expression was associated with LNM in subgroup of nondigestive system malignancies (FPRP $<0.001)$, sample size more than 88 (FPRP $<0.001)$ and studies reported in 2017 (FPRP $<0.001)$. FPR $P$ value and statistical power were shown in Table 3 .

\section{Sensitivity analysis and publication bias}

Sensitivity analysis was performed by using Stata12.0 software to assess whether the individual study affected the overall results. The results showed that individual study had little influence on our final results (Figure 5), thus our results were relatively stable and credible. We used both Begg's test and Egger's test to evaluate publication bias. Begg's funnel plot with pseudo 95\% CIs was provided. Our data didn't revealed publication bias across the studies, including meta-analysis of the association of ZFAS1 expression with OS (Begg's test:Pr $>|Z|=0.602$; Egger's test: $P>|t|=0.459)$ and LNM (Begg's test: $\operatorname{Pr}>|Z|=0.917$; Egger's test:P $>|t|=0.949$ ) (Figure 6).

\section{DISCUSSION}

Recent studies indicated that numberous IncRNAs such as nuclear paraspeckle assembly transcript 1 (NEAT1), cyclin D2 antisense RNA 1 (CCND2-AS1), taurine-upregulated gene 1 (TUG1) and HOX transcript antisense RNA (HOTAIR) were overexpressed in tumors, and involved in tumor occurrence and progression [26-29]. As potential new molecular biomarkers, differential levels of lncRNAs or cancer-specific IncRNA profiles may be used for the prediction of cancer prognosis.
ZFAS1, located at chromosomal band 20q13.13, was first reported dysregulated in breast cancer, suggesting a role of ZFAS1 in this type of cancer [30]. Subsequently, ZFAS1 was confirmed involved in a series of human tumors. For instance, Li et al. showed that ZFAS1 was amplified in HCC, and promoted HCC cell invasion and migration by positively regulating ZEB1, MMP14 and MMP16 [14]. Nie et al. found that ZFAS1 might act as a oncogene in GC by repressing KLF2 and NKD2 expression [15]. Moreover, Wang et al. showed that ZFAS1 was upregulated in CRC, which prompted metastasis of CRC [22]. Recently, studies indicated consistent results about the relationship between high ZFAS1 expression and poorer prognosis in CRC, GC, HCC, glioma, melanoma and NSCLC $[14,15,17$, $18,19,20,22]$. However, there is controversy about the relationship between ZFAS1 expression and LNM in various cancers. Some studies indicated that high ZFAS1 expression was associated with LNM $[16,17,18,19$, $21,22]$, While others showed no significant associated between elevated ZFAS1 levels and LNM $[15,23]$. These findings suggest that ZFAS1 may be a promising indicator of prognosis in human cancers, but further confirmation by extensive analysis is required.

In our meta-analysis, we assessed the association of ZFAS1 expression with metastasis and prognostic outcome. From the available studies, we found that high ZFAS1 expression was associated with poor OS in different types of cancers without significant heterogeneity, suggesting that ZFAS1 may serve as a reliable molecular marker for poor prognosis in various cancers. In addition, we found there was a significant association between ZFAS1 expression and LNM, but with heterogeneity. Therefore, we performed subgroup analysis to precisely assess the association of ZFAS1 with LNM. Subgroup analyses showed a remarkable decrease in the heterogeneity of LNM in subgroups of "sample size more than 88", "non-digestive system malignancies' and "studies reported in 2017", suggesting that "tumor type", "sample size" and "publication year" may be as sources of heterogeneity. Moreover, data from subgroup analysis showed that high ZFAS1 expression was related to high incidence of LNM in the subgroup of sample size $>88$, nondigestive system malignancies and studies reported in 2017, which further strengthened the pooled result. To make our results more reliable, we performed FPRP test, and found that the correlation of high ZFAS1 expression with LNM in subgroup of nondigestive system malignancies, sample size $>88$ and studies reported in 2017 all passed the FPRP test, indicating these associations were reliable.

Taken together, our meta-analysis results indicate that ZFAS1 may act as a novel biomarker in predicting the clinical outcome of cancer patients. Further studies exploring the relationship between LNM and ZFAS1 expression are required to verify its clinical prognostic value in human cancers. 
Table 2: Results of subgroup analysis of increased ZFAS1 expression and LNM in various carcinomas

\begin{tabular}{|c|c|c|c|c|c|c|c|}
\hline \multirow{2}{*}{ Stratified analysis } & \multirow{2}{*}{$\begin{array}{l}\text { No. of } \\
\text { studies }\end{array}$} & \multirow{2}{*}{$\begin{array}{c}\text { No. of } \\
\text { patients }\end{array}$} & \multicolumn{2}{|c|}{ Heterogeneity } & \multirow{2}{*}{$\begin{array}{c}\text { Pooled OR } \\
(95 \% \text { CI) }\end{array}$} & \multirow{2}{*}{$P$-value } & \multirow{2}{*}{$\begin{array}{c}\text { Meta- } \\
\text { regression } \\
P \text { value }\end{array}$} \\
\hline & & & $I_{2}(\%)$ & $P$ value & & & \\
\hline Tumor type & & & & & & & 0.144 \\
\hline Digestive system & 6 & 551 & 72.3 & 0.003 & $1.98(0.97-4.04)$ & 0.062 & \\
\hline Non-digestive system & 3 & 321 & 0 & 0.555 & $4.05(2.49-6.60)$ & $<0.001$ & \\
\hline Sample size & & & & & & & 0.825 \\
\hline Number $\leq 88$ & 4 & 342 & 77.9 & 0.001 & $2.07(0.74-5.74)$ & 0.164 & \\
\hline Number $>88$ & 5 & 530 & 23.2 & 0.272 & $3.16(2.06-4.86)$ & $<0.001$ & \\
\hline NOS score & & & & & & & 0.610 \\
\hline$\leq 6$ & 4 & 407 & 59.7 & 0.059 & $1.51(1.06-2.16)$ & 0.023 & \\
\hline$>6$ & 5 & 465 & 75.3 & 0.003 & $1.62(1.06-2.48)$ & 0.027 & \\
\hline Publication year & & & & & & & 0.069 \\
\hline 2016 & 6 & 630 & 72.6 & 0.003 & $1.94(1.00-3.78)$ & 0.050 & \\
\hline 2017 & 3 & 242 & 0.0 & 0.002 & $4.86(2.67-8.84)$ & $<0.001$ & \\
\hline
\end{tabular}

There are some limitations in our analysis. First, the number of patients and types of cancers included are relatively small. Second, studies included in the metaanalysis all come from People's Republic of China, for this reason, our results may just represent the cases of Chinese cancer patients. Third, positive results can be published more easily than negative ones, which may lead to larvaceous publication bias. Fourth, this meta-analysis is a retrospective analysis, which may limit the conclusion due to selection bias. Fifth, the quality of studies included in

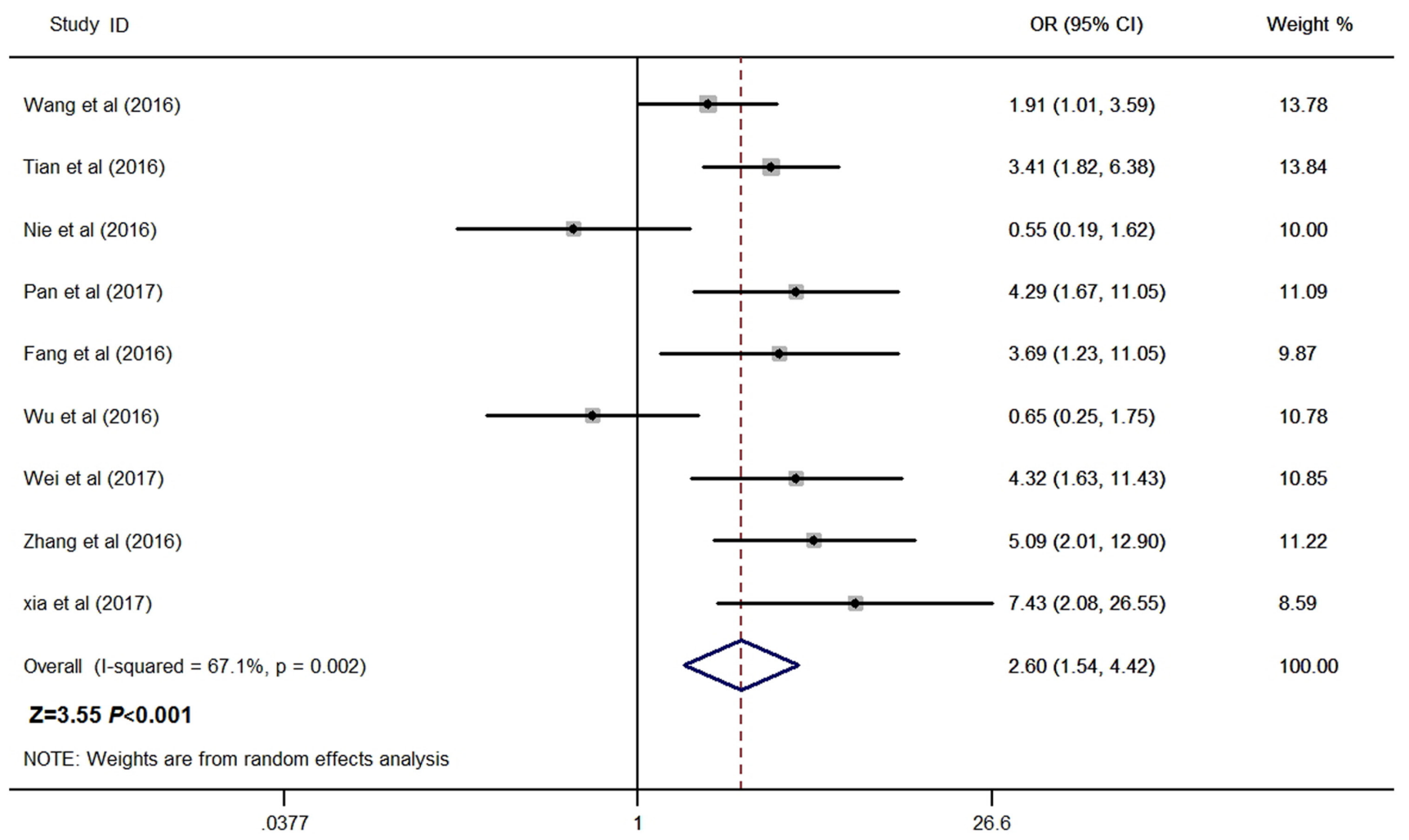

Figure 3: Forest plot for the association between ZFAS1 expression with LNM. 

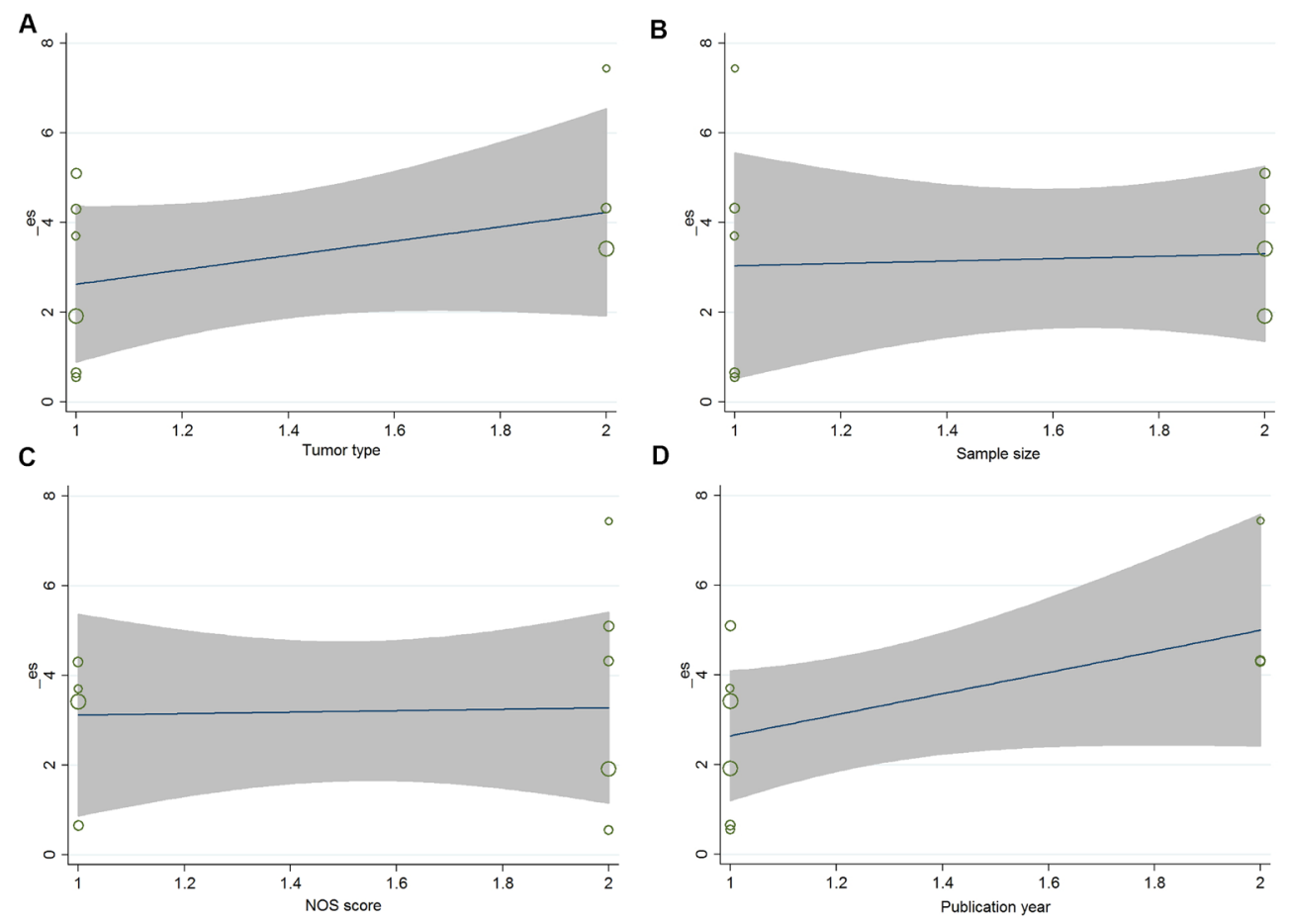

Figure 4: (A) Based on tumor type ; (B) Based on sample size; (C) Based on NOS score; (D) Based on publication year.
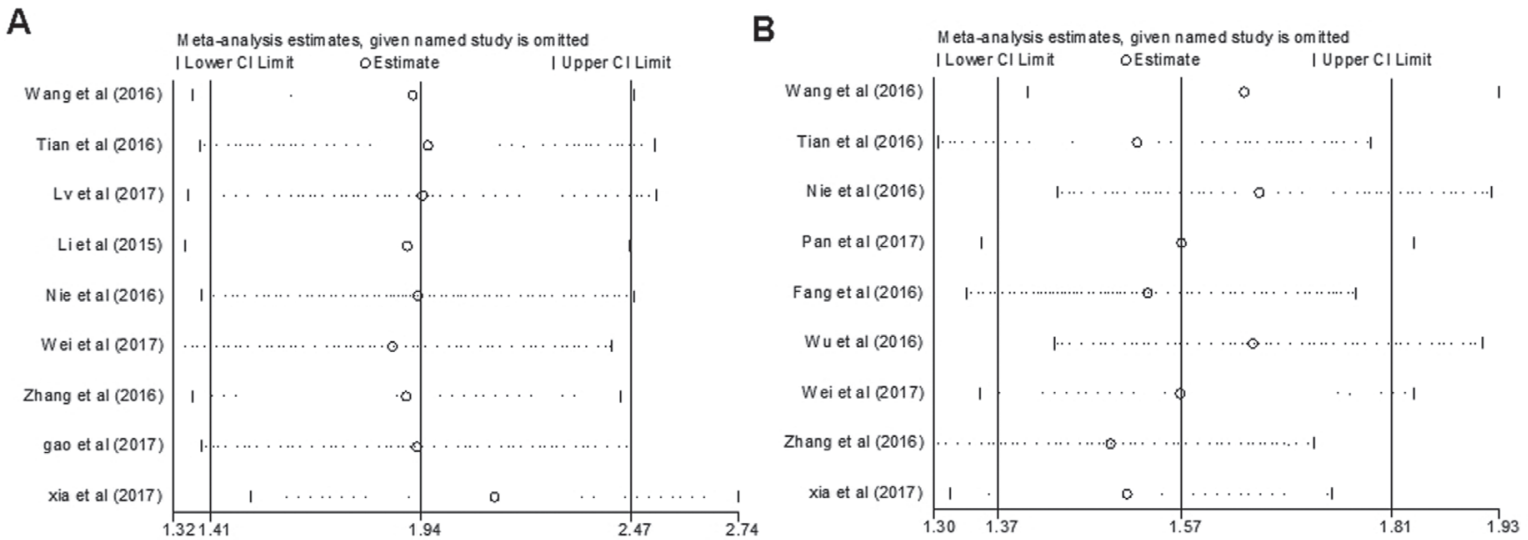

Figure 5: Sensitivity analyses of the studies. (A) Overall survival; (B) Lymph node metastasis.
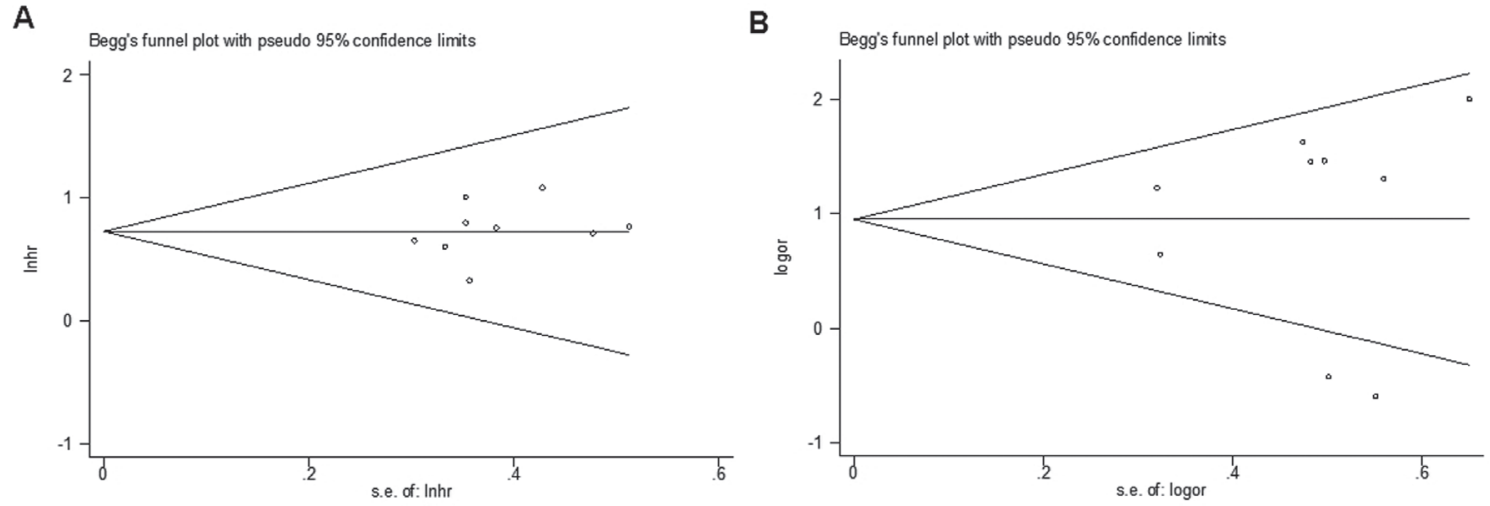

Figure 6: Begg's test for publication bias. (A) Overall survival; (B) Lymph node metastasis. Abbreviations: SE, standard error. 
Table 3: False-positive report probability values for associations between increased ZFAS1 expression and LNM in various carcinomas

\begin{tabular}{|c|c|c|c|c|c|c|c|c|}
\hline \multirow{2}{*}{ Stratified analysis } & \multirow{2}{*}{$\begin{array}{c}\text { Pooled OR } \\
(95 \% \text { CI) }\end{array}$} & \multirow{2}{*}{$P$-value } & \multirow{2}{*}{$\begin{array}{c}\text { Statistical } \\
\text { Power }\end{array}$} & \multicolumn{5}{|c|}{ Prior probability } \\
\hline & & & & 0.25 & 0.1 & 0.01 & 0.001 & 0.0001 \\
\hline \multicolumn{9}{|l|}{ Tumor type } \\
\hline Digestive system & $1.98(0.97-4.04)$ & 0.062 & 0.564 & 0.243 & 0.491 & 0.914 & 0.991 & 0.999 \\
\hline Non-digestive system & $4.05(2.49-6.60)$ & $<0.001$ & 0.520 & $<0.001$ & $<0.001$ & $<0.001$ & $<0.001$ & $<0.001$ \\
\hline \multicolumn{9}{|l|}{ Sample size } \\
\hline Number $\leq 88$ & $2.07(0.74-5.74)$ & 0.164 & 0.511 & 0.471 & 0.727 & 0.967 & 0.997 & 1.000 \\
\hline Number $>88$ & $3.16(2.06-4.86)$ & $<0.001$ & 0.523 & $<0.001$ & $<0.001$ & $<0.001$ & $<0.001$ & 0.003 \\
\hline \multicolumn{9}{|l|}{ NOS score } \\
\hline$\leq 6$ & $1.51(1.06-2.16)$ & 0.023 & 0.485 & 0.129 & 0.308 & 0.831 & 0.980 & 0.998 \\
\hline$>6$ & $1.62(1.06-2.48)$ & 0.027 & 0.362 & 0.180 & 0.396 & 0.878 & 0.986 & 0.999 \\
\hline \multicolumn{9}{|l|}{ Publication year } \\
\hline 2016 & $1.94(1.00-3.78)$ & 0.050 & 0.536 & 0.224 & 0.464 & 0.905 & 0.990 & 0.999 \\
\hline 2017 & $4.86(2.67-8.84)$ & $<0.001$ & 0.537 & $<0.001$ & $<0.001$ & $<0.001$ & $<0.001$ & 0.004 \\
\hline
\end{tabular}

the meta-analysis was uneven and thus limit the precision and generalizability of the pooled estimates. Finally, these studies lack a unified criterion for high ZFAS1 expression. Therefore, larger-scale, multicenter, and higher-quality studies are required to confirm our findings in the future.

\section{ACKNOWLEDGMENTS AND FUNDING}

The authors would sincerely thank all subjects and all medical staff who participated in this study. This study was funded by the National Natural Science Foundation of China (81502107) and Natural Science Foundation of Liaoning Province (2014021036 and 20170540560).

\section{CONFLICTS OF INTEREST}

The authors report no conflicts of interest in this work.

\section{REFERENCES}

1. Siegel RL, Miller KD, Jemal A. Cancer statistics, 2016. CA Cancer J Clin. 2016; 66:7-30. https://doi.org/10.3322/ caac. 21332 .

2. Ferlay J, Soerjomataram I, Dikshit R, Eser S, Mathers C, Rebelo M, Parkin DM, Forman D, Bray F. Cancer incidence and mortality worldwide: sources, methods and major patterns in GLOBOCAN 2012. Int J Cancer. 2015; 136:E359-86. https://doi.org/10.1002/ijc.29210.

3. Stoffel EM, Yurgelun MB. Genetic predisposition to colorectal cancer: implications for treatment and prevention.
Semin Oncol. 2016; 43:536-42. https://doi.org/10.1053/j. seminoncol.2016.08.002.

4. Chang JC, Kundranda M. Novel Diagnostic and Predictive Biomarkers in Pancreatic Adenocarcinoma. Int J Mol Sci. 2017; 18:E667. https://doi.org/10.3390/ijms18030667.

5. Mercer TR, Dinger ME, Mattick JS. Long non-coding RNAs: insights into functions. Nat Rev Genet. 2009; 10:155-59. https://doi.org/10.1038/nrg2521.

6. Ponting CP, Oliver PL, Reik W. Evolution and functions of long noncoding RNAs. Cell. 2009; 136:629-41. https://doi. org/10.1016/j.cell.2009.02.006.

7. Previdi MC, Carotenuto P, Zito D, Pandolfo R, Braconi C. Noncoding RNAs as novel biomarkers in pancreatic cancer: what do we know? Future Oncol. 2017; 13:443-53. https:// doi.org/10.2217/fon-2016-0253.

8. Weng $\mathrm{M}, \mathrm{Wu} \mathrm{D}$, Yang $\mathrm{C}$, Peng $\mathrm{H}$, Wang G, Wang $\mathrm{T}$, Li $\mathrm{X}$. Noncoding RNAs in the development, diagnosis, and prognosis of colorectal cancer. Transl Res. 2017; 181:10820. https://doi.org/10.1016/j.trsl.2016.10.001.

9. Takenaka K, Chen BJ, Modesitt SC, Byrne FL, Hoehn KL, Janitz $\mathrm{M}$. The emerging role of long non-coding RNAs in endometrial cancer. Cancer Genet. 2016; 209:445-55. https://doi.org/10.1016/j.cancergen.2016.09.005.

10. Li G, Zhang H, Wan X, Yang X, Zhu C, Wang A, He L, Miao R, Chen S, Zhao H. Long noncoding RNA plays a key role in metastasis and prognosis of hepatocellular carcinoma. Biomed Res Int. 2014; 2014:780521. https:// doi.org/10.1155/2014/780521.

11. Yao Y, Li J, Wang L. Large intervening non-coding RNA HOTAIR is an indicator of poor prognosis and a therapeutic target in human cancers. Int J Mol Sci. 2014; 15:18985-99. https://doi.org/10.3390/ijms151018985. 
12. Cai B, Wu Z, Liao K, Zhang S. Long noncoding RNA HOTAIR can serve as a common molecular marker for lymph node metastasis: a meta-analysis. Tumour Biol. 2014; 35:8445-50. https://doi.org/10.1007/s13277-0142311-4.

13. Cheetham SW, Gruhl F, Mattick JS, Dinger ME. Long noncoding RNAs and the genetics of cancer. Br J Cancer. 2013; 108:2419-25. https://doi.org/10.1038/bjc.2013.233.

14. Li T, Xie J, Shen C, Cheng D, Shi Y, Wu Z, Deng X, Chen H, Shen B, Peng C, Li H, Zhan Q, Zhu Z. Amplification of long noncoding rna zfas1 promotes metastasis in hepatocellular carcinoma. Cancer Res. 2015; 75:3181-91. https://doi.org/10.1158/0008-5472.CAN-14-3721.

15. Nie F, Yu X, Huang M, Wang Y, Xie M, Ma H, Wang Z, De W, Sun M. Long noncoding RNA ZFAS1 promotes gastric cancer cells proliferation by epigenetically repressing KLF2 and NKD2 expression. Oncotarget. 2017; 8:38227-38. https://doi.org/10.18632/oncotarget.9611.

16. Pan L, Liang W, Fu M, Huang ZH, Li X, Zhang W, Zhang P, Qian H, Jiang PC, Xu WR, Zhang X. Exosomes-mediated transfer of long noncoding RNA ZFAS1 promotes gastric cancer progression. J Cancer Res Clin Oncol. 2017; 143:991-1004. https://doi.org/10.1007/s00432-017-2361-2.

17. Zhang JJ, Chen JT, Yao KH, Hua L, Wang CY, Hu JH. Up-regulated expression of long non-coding RNA ZFAS1 associates with aggressive tumor progression and poor prognosis in gastric cancer patients. Int J Clin Exp Pathol. 2016; 9:2059-63.

18. Wei YH, Fu Y, Luo HJ, Li R, Li HY. Higher expression of ZFAS1 is associated with poor prognosis in malignant melanoma and promotes cell proliferation and invasion. Int J Clin Exp Pathol. 2017; 10:4640-46.

19. Tian FM, Meng FQ, Wang XB. Overexpression of longnoncoding RNA ZFAS1 decreases survival in human NSCLC patients. Eur Rev Med Pharmacol Sci. 2016; 20:5126-31.

20. Lv QL, Chen SH, Zhang X, Sun B, Hu L, Qu Q, Huang YT, Wang GH, Liu YL, Zhang YY, Zhou HH. Upregulation of long noncoding RNA zinc finger antisense 1 enhances epithelial-mesenchymal transition in vitro and predicts poor prognosis in glioma. Tumour Biol. 2017; 39. https://doi. org/10.1177/1010428317695022.

21. Fang C, Zan J, Yue B, Liu C, He C, Yan D. Long noncoding rna zfas1 promotes the progression of colonic cancer by modulating zeb1 expression. J Gastroenterol Hepatol. 2017; 32:1204-11. https://doi.org/10.1111/jgh.13646.
22. Wang W, Xing C. Upregulation of long noncoding RNA ZFAS1 predicts poor prognosis and prompts invasion and metastasis in colorectal cancer. Pathol Res Pract. 2016; 212:690-95. https://doi.org/10.1016/j.prp.2016.05.003.

23. Wu L. The expression and biological function of long noncoding RNA linc00467 and ZFAS1 in human sporadic colorectal cancer [D]China: Peking Union Medical College. 2016.

24. Tierney JF, Stewart LA, Ghersi D, Burdett S, Sydes MR. Practical methods for incorporating summary time-to-event data into meta-analysis. Trials. 2007; 8:16. https://doi. org/10.1186/1745-6215-8-16.

25. Wacholder S, Chanock S, Garcia-Closas M, El Ghormli L, Rothman N. Assessing the probability that a positive report is false: an approach for molecular epidemiology studies. $\mathrm{J}$ Natl Cancer Inst. 2004; 96:434-42. https://doi.org/10.1093/ jnci/djh075.

26. Yang C, Li Z, Li Y, Xu R, Wang Y, Tian Y, Chen W. Long non-coding RNA NEAT1 overexpression is associated with poor prognosis in cancer patients: a systematic review and meta-analysis. Oncotarget. 2017; 8:2672-80. https://doi. org/10.18632/oncotarget.13737.

27. Zhang H, Wei DL, Wan L, Yan SF, Sun YH. Highly expressed lncRNA CCND2-AS1 promotes glioma cell proliferation through $\mathrm{Wnt} / \beta$-catenin signaling. Biochem Biophys Res Commun. 2017; 482:1219-25. https://doi. org/10.1016/j.bbrc.2016.12.016.

28. Katsushima K, Natsume A, Ohka F, Shinjo K, Hatanaka A, Ichimura N, Sato S, Takahashi S, Kimura H, Totoki Y, Shibata T, Naito M, Kim HJ, et al. Targeting the Notchregulated non-coding RNA TUG1 for glioma treatment. Nat Commun. 2016; 7:13616. https://doi.org/10.1038/ ncomms 13616.

29. Liu S, Zhang M, Qu P. Expression level and clinical significance of HOX transcript antisense intergenic RNA in cervical cancer: a meta-analysis. Sci Rep. 2016; 6:38047. https://doi.org/10.1038/srep38047.

30. Askarian-Amiri ME, Crawford J, French JD, Smart CE, Smith MA, Clark MB, Ru K, Mercer TR, Thompson ER, Lakhani SR, Vargas AC, Campbell IG, Brown MA, et al. SNORD-host RNA Zfas1 is a regulator of mammary development and a potential marker for breast cancer. RNA. 2011; 17:878-91. https://doi.org/10.1261/rna.2528811. 